\title{
The Uses of Chlorella Vulgaris as Antimicrobial Agent and as a Diet: the Presence of Bio-active Compounds which caters the Vitamins, Minerals in General
}

\author{
Shabudeen Syed *, Ashok Arasu and Indhumathi Ponnuswamy \\ Department of Chemistry, Kumaraguru College of Technology, Coimbatore. India, \\ shabu_cbe@yahoo.com,ashokbiotech16@gmail.com,cuteindhu@gmail.com
}

\begin{abstract}
The extracted and dried green micro algae by using solvents Acetone, Ethanol and Chloroform assy is tested to know its efficiency against four bacterial strains under the cultured condions by adopting the standard agar disc diffusion technique. These agar plates are incubated at $37^{\circ} \mathrm{C}$ for 24 hour duration with four test bacterial strains in $10 \mathrm{ml}$ each of Acetone,Ethanol and Chloroform with extracted green micro algae. These extracts exhibits optimal effects on inhibitory efficiency. The observed highest inhibition zone zone is $13 \mathrm{~mm}$ in Chlorella Vulgaris extracted with Ethanol against klebsilla sp... The peroformed preliminary phytochemical analysis of this dried algal sample as per the Harborne methode reveals that this assay withhold some of the valuble bioactive compounds. It is flavanoids, tannin, phenolic compounds, terpenes, cardiac glycosides, saponins and carbohydrates. The substanical evidence of the presence of these seven bioactive compounds revealed that Chlorella vulgar is having major role as a useful precarusor to obtain various bioactive compounds. This algael specices exhibits its maximum inhibition property with Klebsilla sp. This enables to discover some of new derivatives with more investigation about its feasilbility of finding new drugs by the application of procdures adopted in drug discovery and designing. The drugs derived from these algae species will find some specific application to curtile the growth of the bacterias which results the control of Vector infections without any side effects in a more specific manner.
\end{abstract}

Keywords: Chlorella vulgaris, ethanol,acetone,chloroform, antimicrobial activity, phytochemical activity

\section{Introduction}

Algae are a rich resource for pharmaceuticals on the basics of presence of these biologically active primary and secondary metabolic compounds [1]. The secondary metabolites presents in the Algae is in favor of organizing a numerous biological defense systems and they act against predation, herbivores and competes for a space [2].

The utility research studies based on Algal Bio Mass produced [12] was pharmaceutically important with respect to a first investigation reporting its antibiotic activities. The extensive research reports indicate that it has already been utilized as a traditional medicine, the highlights are of bacteria-static, bactericidal, antifungal, antiviral and antitumor activities. The abilities are due to the presence of fatty acids in these micro algae organisms, which develops antibacterial activity [4]. The anti bacterial activities are exhibited by the volatile extracts of Spirulina platensis, reports that it contains a "phytochemical compound" which is found in this plants are undergoing pharmacological interactions with the nutrients and dietary fibers which enables the humans in protecting them self against the diseases and 
there are some interesting reports that their ability in slowing down the aging process. The studies which lead to the discovery of the medicinal plants with lot of medicinal values are referred as Phytochemical screening. It is wondered, without the understanding the basic knowledge about the cellular actions or metabolic reaction mechanisms, basic functionalities of these phytochemicals (Algae), and from the period of Hippocrates they are administrated as effective drugs. Few reports in the literature states that willow tree leaves were prescribed to abate fever and Salicin was prescribed for anti-inflammatory and pain relieving medicine. This has been extracted from the bark of white willow tree and it is used to synthesis staple and it is proven that it is the counter drug for aspirin [3]. These remarkable aspects encourage to investigate this phytochemical and its derivatives and validate its effectiveness as antibacterial character is present with Chlorella vulgaris a micro organism. As per the reports avialble in literature, the anti microbial substances are unsaturated lactones, cyanogenicglycosides, sulphur containing compounds, phenols, phenolicglycosides, saponins and phytoalexins [5]. The therapeutic use of algae has reported from 1950s and some of the systematic drug discoveries of algae and biologically active substances of antibiotics were reported.The positive and negative gram baterial tests were carried out by the aqueous and solvent extracts of this algae [6] due to the presence of fatty acids, acrylic acid, halogenated aliphatic compounds, terpenes, sulphur containing hetero cyclic compounds, carbohydrates and phenols [7] in this system it posses antimicrobial character. Various results in-vitro antifungal activities of these extracts of green micro algae, diatoms and dinoflagellates have already been reported [8].

Very important major living and renewable resources Microalgae constitutes with carbon sequestration abilities contains more than sixty trace elements which includes minerals, iodine, bromine, proteins with bioactive substances. The Chemically Unique compounds with various biological activities of this fresh water algae micro organisam have been isolated and few are under investigation, fewer are utilized to discover the drugs [9] In this efforts few bioactive, pharmacological substances have already been isolated [14].The antimicrobial activities of these plant-based algae species have negligible side effects and have valuble therapeutic potential rather than the synthetic antimicrobials.

\section{Materials and Methods}

The sample microalgae species chlorella vulgaris sp was collected from Erode and Coimbatore surface lake water bodies. The algal sample was cleaned and necrotic parts were removed. Then the sample was rinsed with sterile water to remove any associated debris. The pure culture of the sample was incubated in water medium.Pure cultures prior to the stationary phase of growth (10 days) were harvested and collected by centrifuging at 10,000 rpm for $3 \mathrm{~min}$. The Collected micro algal pellets were dried under shade and made into a coarse powder with mechanical grinder for further use. The algal dried powders $(20 \mathrm{gm})$ were successively extracted using serial Exhaustive Extraction Method with Chloroform, Acetone, Ethanol solvents. The dry powders of each extract were resuspended in the respective organic solvents at a concentration of $100 \mathrm{mg} / \mathrm{ml}$ for further phytochemical screening and antimicrobial activity.

\section{Bacterial Strain Used}

The following bacterial strain were used for this present study

- Escherichia coli.

- Bacillus sp.

- Klebsiella sp. 


\section{Preparation of Extracts}

\section{Crude method}

The sample of $1 \mathrm{gm}$ was transferred into clean screw cap bottle of $10 \mathrm{ml}$ capacity. Solvent of $10 \mathrm{ml}$ is added separately. The extracts are separated and collected for storing at $4{ }^{\circ} \mathrm{C}$ and utilised for the remaining analysis is to be carried out.

\section{Determination of Antimicrobial Activity}

The test organisms subject for determination of antimicrobial activity are swabbed on the air dried nutrient agar plates by using sterile cotton swabs. The steriled discs are loaded with varying concentration of Chlorella vulgaris. The flame sterile disc loaded with $150 \mu \mathrm{l}$ of sample extracts are placed with the surface of nutrient agar plates and swabbed bacterial cultures. The discs loaded with proper solvents as prescribed and controls are incorporated in order to maintain the culture at the incubation temperature of $37^{\circ} \mathrm{C}$ atlease for 24 hours. The antimicrobial activity is to be determined as per the normal procedure by measuring the zone of inhibition around the discs the diameter of the inhibition zone is measured exactly with the help of physical scales in millimeters.

\section{Preliminary Phytochemical Screening}

A systematic and complete study of crude drugs includes with complete investigation of both primary and secondary metabolites obtained from derived plant metabolisms. Various qualitative test as perscribed by standard procedure are carried out and various profiles are established for various extracts according to their chemical composition in nature ${ }^{11,13 \& 15}$. The extracts obtained are subjected to chemical tests as normal routine procedure in identification of various phytoconstituents which are followed as protocol as per the methods adopted by Harborne.

\section{Results and Discussion}

\section{Antimicrobial Activity of Chlorella Vulgaris:}

The antimicrobial activity of Chlorella vulgaris was carried out to determine inhibition against some of the common pathogen like E.coli, Klebsilla sp., bacillus sp. and Pseudomonas sp. which are pathegeonic to humans and considered to cause water borne and vector diseases and is causing drastic impacts with huge impacts [10, 12].

The effect of Acetone, Ethanol, Chloroform extracted micro algae is tested for its inhibition efficiency in which,the Ethanol extracted sample showed the maximum inhibitory activity against klebsilla sp. $(17 \mathrm{~mm})$. where as the E.coli $(15 \mathrm{~mm})$, Bacillus $s p .(13 \mathrm{~mm})$ and Pseudomonas (12mm), with exhibition of minimum inhibitory zone. The Acetone extract of the sample showed a maximum inhibitory activity against Bacillus $s p .(15 \mathrm{~mm})$. Where the as Pseudomonas (13mm) and klebsilla sp. (12 $\mathrm{mm})$ and E.coli (08) show a minimum inhibitory zone. The chloroform extract of the sample showed the maximum inhibitory activity against Bacillus sp. (14mm).with E.coli $(12 \mathrm{~mm})$, Pseudomonas $(11 \mathrm{~mm})$ and klebsilla sp. $(10 \mathrm{~mm})$, a minimum inhibitory zone. As per the avilable details of Tetracycline the maximum inhibitory the activity against. klebsilla sp. (18mm) against Bacillus sp. (16mm),against Pseudomonas $(15 \mathrm{~mm})$, and against E.coli $(13 \mathrm{~mm})$ with minimum inhibitory zone (Table 1).

A very sensitive and a important phytochemical screening of the Chlorella vulgaris fraction are performed. It reveals the level of Flavonoids, Tannin, Phenolic compounds, 
Terpenoids, Cardiac, glycosides, Saponins and Carbohydrates with positive results with the help of ethanol extract (Table 1).

Table 1. Antimicrobial Activity of Chlorella Vulgaris Extracted with Acetone, Ethanol and Chloroform. (Values are in millimeter)

\begin{tabular}{|c|c|c|c|c|}
\hline \multirow{2}{*}{$\begin{array}{l}\text { S.N } \\
\text { o }\end{array}$} & \multirow[t]{2}{*}{ Organisms } & \multicolumn{3}{|c|}{ Zone of inhibition in Diameter } \\
\hline & & $\begin{array}{c}\text { Aceton } \\
\text { e }\end{array}$ & $\begin{array}{c}\text { Ethano } \\
\text { l }\end{array}$ & $\begin{array}{c}\text { Chlorofor } \\
\text { m }\end{array}$ \\
\hline 1. & E.coli & 8 & 15 & 12 \\
\hline 2. & Klebsilla sp. & 12 & 17 & 10 \\
\hline 3. & Bacillus sp. & 15 & 13 & 14 \\
\hline 4. & $\begin{array}{l}\text { Pseudomona } \\
s\end{array}$ & 13 & 12 & 11 \\
\hline \multicolumn{5}{|c|}{ Phytochemical screening of Chlorella vulgaris } \\
\hline 5. & Flavonoids & \multicolumn{3}{|c|}{ Positive } \\
\hline 6. & Tannin & \multicolumn{3}{|c|}{ Positive } \\
\hline 7. & $\begin{array}{l}\text { Phenolic } \\
\text { compounds }\end{array}$ & \multicolumn{3}{|c|}{ Positive } \\
\hline 8. & Terpenoids & \multicolumn{3}{|c|}{ Positive } \\
\hline 9. & Cardiac glycosides & \multicolumn{3}{|c|}{ Positive } \\
\hline 10. & Saponins & \multicolumn{3}{|c|}{ Positive } \\
\hline 11. & Carbohydrates & \multicolumn{3}{|c|}{ Positive } \\
\hline
\end{tabular}

\section{Conclusions}

As per the growth rate assessments and carbon sequestration capabilities and in testing its microbial inhibition character, it is concluded that this algae is having its ability of sequesrating carbon level in atmosphere and nitrate,phosphate,suplphate loads of waters, and it proves its worthiness in extracting bio-fuel.

The present research enables to know the ability of this micro-algae species to promote as an antimicrobial agent. This inhibitation efficiency is mainly due to the presence of stable biologically active compounds. The bio active compounds presents in this system will have some specific chemical structures which enables to functions it as a beneficial substance and creates the effects of inhibition of harmful pathogens. The negligible side effect of this microalgae species draws some of special interest to promote it in the form of a new medicinal food supplement.This micro algae will helps the living organisms to increase immunity even to humans, in order to confirm the results proper permissions are needed to carry out research trails with immuno modulated studies.

The reason behind it to be used as food supplement with anti microbial charater is due to the presence of Flavonoids which are possessing vitamin like properties. The earlier research finding proposed that a short lived vitamin $\mathrm{P}$ is present in these type of compounds which contains flavonoids and the plants containing flavonoids are used by the folks to treate the disorders with respect to thyroid and other hormons difficiencies. Some of the recent investigation also identify that they possess antioxidant and antimicrobial, anti mutagenic, anti carcinogenic properties. The informations on tannins attributed to the wound-healing and anti-inflammatory properties, the Phenolic compounds are considere to be an essential part of 
the human dietary methods since it contains antioxidant properties, Terpenes are finds its use as an anti-spasmodic, carminative and stimulant, with an effective antiseptic property. It is usfuel in treating cold and fever, headache and body aches due to its ability to decrease inflammation. The anti-spasmodic (sedative) nature helps inhailing the pains in the bowel and its muscles. The theraapeutic application of Cardiac glycosides finds its therapeutic application due to positive isotropic effects which enables it to treat heart-related pathologies. More recently, considerable in vitro, in vivo and epidemiological data support the roles for such drugs for the treatment of several diseases [6]. Saponins are having some strong antitumor effects and found beneficial in targeting and inhibiting the tumor angiogenesis by suppressing its inducer in the endothelial cells in blood vessels and preventing and adhering, invasion of metastasis of tumor cells. Carbohydrate are used in the field of skin tissue engineering, wound healing modulation and a food material. All these essential bio active compounds are present in the cholrella vulgaris sample and it is to be refined and could be utilised as food supllement as well as medicine.This study enables to pave a way to discover a new drug and field trials are to be needed with proper licencing procdures.

\section{Acknowledgements}

The authors wish to express the gratitude for the support and financial help given by Department of Science and Technology, New Delhi for their support under Net Work Programme of Bio-Alge Carbon Sequestration research under the title "Carbon Sequestration and cultivating algae for green bio-fuel Production" and to PadmaBhusan, Dr. Arutselvar N. Mahlingam, Chairman Kumaraguru College of Technology.

\section{References}

[1] K. S. Diker, M. Akan, G. Hascelik and M. Yurdakok, ,The bactericidal activity of tea against Campylobacter jejuni and Campylobacter coli. Lett Appl Microbiol“, vol. 12, (1991), pp. 34-54.

[2] J. A. Findlay and A. D. Patil, „Antibacterial constituents of the diatom Navicula delogne “, Journal of Natural Products, vol. 47, (1984), pp. 815-818.

[3] Y. Ghasemi, M. T. Yazdi, A. Shafiee, M. Amini, S. Shokravi and G. Zarrini, „Parsiguine, a novel antimicrobial substance from Fischerella ambigua “, Pharmaceutical Biology, vol. 42, (2004), pp. 318-322.

[4] A. Gonzalez del Val, G. Platas and A. Basilio, ,Screening of antimicrobial activities in red, green and brown macroalgae from Gran Canaria (Canary Islands, Spain) “, Int.Microbiol, vol. 4, (2001), pp. 35-40.

[5] B. Harborne, „Phytochemical Methods: A Guide to Modern Techniques of Plant Analysis“, 3rd Edition. Chapman \& Hall Pub. London, UK, (1998).

[6] M. Herrero, E. Ibañez, A. Cifuentes, G. Reglero and S. Santoyo, „Dunaliella salina microalga pressurized liquid extracts as potential antimicrobials“, Journal of Food Protection, vol. 69, (2006), pp. 2471-2477.

[7] G. Z. Justo, M. R. Silva and M. L. Queiroz, ,SEffects of green algae chlorella vulgaris on the response of the host hematopoietic system to intraperitoneal ehrlich ascites tumour transplantation in mice“, J. Algal Biomass Utln., vol. 2, no. 3, (2011), pp. 74-81.

[8] K. Y Kim, P. M. Davidson and H. J. Chung, ,Antibacterial activity in extracts of Camellia japonica L. petals and its application to a model food system", J Food Prot, vol. 64, (2001), pp. 1255-60.

[9] J. A. Mendiola, C. F. Torres, P. J. Martín-Alvarez, S. Santoyo, A. Toré, B. O. Arredondo, F. J. Señoráns, A. Cifuentes and E. Ibáñez, „Use of supercritical CO2 to obtain extracts with antimicrobial activity from Chaetoceros muelleri microalga", A correlation with their lipidic content. European Food Research and Technology, vol. 224, (2007), pp. 505-510.

[10] B. Metting and J. W. Pyne, „Biologically active compounds from microalgae“, Enzyme and Microbial Technology, vol. 8, (1986), pp. 386-394.

[11] E. Ryu, D. C. Blenden and D. Wendall, „The inhibition of growth of selected bacteria by incorporating powdered tea in the medium", Int J Zoonoses, vol. 9, (1982), pp. 73-75.

[12] P. S. Syed Shabudeen, M. Soundrarajan and P. Indumathi, "Algae biomass growth kinetic study in wasteWater medium using spectroscopic analysis", Journal of Environmental Research And Development, vol. 7, no. 4A, April-June (2013). 
[13] M. Toda, S. Okubo, R. Hiyoshi and T. Shimamura, „The bactericidal activity of tea and coffee“, Lett Appl Microbiol, vol. 8, no. 6, (1989), pp. 123-5.

[14] J. Tramper, C. Battershill, W. Brandenburg, G. Burgess, R. Hill, E. Luiten, W. Müller, R. Osinga, G. Rorrer, M. Tredici, M. Uriz, P. Wright and R. Wijffels, „What to do in marine biotechnology?“, Biomolecular Engineering, (2003), pp. 20467-471.

[15] R. Uma, V. Sivasubramanian and S. Niranjali Devaraj, „Preliminary phycochemical analysis and in vitro antibacterial screening of green micro algae“, Desmococcus Olivaceous, Chlorococcum humicola and Chlorella vulgaris Vivekananda Institute of Algal Technology (VIAT), RKM Vivekananda College, Chennai, INDIA. Department of Biochemistry, University of Madras, Guindy, Chennai, INDIA. 